\title{
Pengaruh Model Pembelajaran CORE (Connecting, Organizing, Reflecting, Extending) terhadap Kemampuan Koneksi Matematis Siswa di SMP Negeri 206 Jakarta
}

\author{
Sigit Galih Nugroho ${ }^{1, \text { a) }}$, Fariani Hermin Indiyah ${ }^{1}$, Aris Hadiyan Wijaksana ${ }^{1}$ \\ ${ }^{1}$ Universitas Negeri Jakarta, Rawamangun, Jakarta Timur \\ Email penulis: ${ }^{\text {a) }}$ sigitgalihn@gmail.com
}

\begin{abstract}
This study aims to determine whether there is a significant effect of the application of the CORE learning model (Connecting, Organizing, Reflecting, Extending) on students' mathematical connection abilities. This research was conducted on eighth grade students at SMP Negeri 206 Jakarta in the even semester of the 2019/2020 academic year on Pythagorean material. The research method used is a quasi-experimental design (quasiexperimental). Sampling using simple random sampling technique. The simple random sampling technique is carried out by randomly selecting two of the four classes that are normally distributed, homogeneous, and have the same average to serve as the experimental class (CORE learning model and the control class (conventional learning model). The research instrument used was a mathematical connection ability test on the Pythagorean material as many as 4 description questions. Before being used, the instrument has been tested for content validity, construct validity, and empirical validity. The reliability calculation was carried out using the Cronbach Alpha formula and obtained a reliability coefficient of $r_{-} 11=0.798$ which was included in the high category. Based on the calculation of the research data, the data for the two classes came from a normally distributed population and had the same or homogeneous variance. Therefore, statistical hypothesis testing was carried out using t-test statistics with the same variance. Based on the results of hypothesis testing, the value of $t_{\text {count }}=$ $1.745>t_{\text {table }}=1.668$, which means rejecting $\mathrm{H}_{0}$ at a significance level of $=0.05$. Thus, it can be concluded that there is a significant effect of the CORE (Connecting, Organizing, Reflecting, Extending) learning model on the mathematical connection abilities of students at SMP Negeri 206 Jakarta on Pythagorean material with a significance level of $=0.05$.
\end{abstract}

Keywords: CORE learning model, Mathematical Connection ability.

\begin{abstract}
Abstrak
Penelitian ini bertujuan untuk mengetahui apakah terdapat pengaruh signifikan penerapan model pembelajaran CORE (Connecting, Organizing, Reflecting, Extending) terhadap kemampuan koneksi matematis siswa. Penelitian ini dilakukan pada siswa kelas delapan di SMP Negeri 206 Jakarta semester genap tahun ajaran 2019/2020 pada materi Pythagoras. Metode penelitian yang digunakan adalah quasi experimental design (eksperimen semu). Pengambilan sampel menggunakan teknik simple random sampling. Teknik simple random sampling dilakukan dengan memilih secara acak dua dari empat kelas berdistribusi normal, homogeny, dan memiliki kesamaan rata-rata untuk dijadikan sebagai kelas eksperimen (model pembelajaran CORE dan kelas kontrol (model pembelajaran konvensional). Instrument penelitian yang digunakan adalah tes kemampuan koneksi matematis pada materi Pythagoras sebanyak 4 soal uraian. Sebelum digunakan, instrument tersebut telah melalui uji validitas isi, validitas konstruk, dan validitas empiris. Perhitungan reliabilitas dilakukan menggunakan rumus Alpha Cronbach dan diperoleh koefisien reabilitas sebesar $r_{11}=0,798$ yang termasuk dalam kategori tinggi. Berdasarkan perhitungan data hasil penelitian, data kedua kelas berasal dari populasi berdistribusi normal dan memiliki varians yang sama atau homogen. Oleh karena itu, pengujian hipotesis statistik dilakukan menggunakan statistik uji- $t$ dengan varians yang sama. Berdasarkan hasil pengujian hipotesis diperoleh nilai $t_{\text {hitung }}=1.745>t_{\text {tabel }}=1,668$, yang artinya tolak $H_{0}$ pada taraf signifikansi $\alpha=0.05$. Dengan demikian dapat disimpulkan bahwa terdapat pengaruh signifikan model pembelajaran CORE (Connecting, Organizing, Reflecting, Extending) terhadap kemampuan koneksi matematis siswa SMP Negeri 206 Jakarta pada materi Pythagoras dengan taraf signifikansi $\alpha=0,05$.
\end{abstract}

Kata kunci: Model pembelajaran CORE, kemampuan Koneksi matematis.

Copyright (c) 2021 Nugroho, Indiyah, Wijaksana

$\triangle$ Corresponding author:

Email Address: sigitgalihn@gmail.com

Received 3 Februari 2020, Accepted 10 Februari 2020, Published 20 Februari 2020

https://doi.org/10.21009/jrpmj.v2i1.12128 


\section{LATAR BELAKANG}

Matematika merupakan ilmu universal yang menjadi dasar perkembangan teknologi dan ilmuilmu lainnya saat ini. Tanpa kita sadari dalam kehidupan sehari-hari, sangat banyak hal-hal yang berhubungan dengan matematika. Hal yang sederhana seperti seorang ibu yang belanja kebutuhan sehari-hari di pasar. Tanpa ilmu matematika, kita tidak dapat menghitung berapa jumlah barang yang dibeli, berapa jumlah uang yang harus dibayarkan, dan lainnya.

Tujuan pembelajaran matematika yang dirumuskan oleh National Council of Teacher of Mathematics (NCTM) (2000) meliputi: (1) pemecahan masalah (problem solving); (2) penalaran (reasoning); (3) komunikasi (communications); (4) koneksi (connections); (5) representasi (representations). Dari lima aspek kemampuan standar yang penting dicapai dalam pembelajaran menurut NTCM, salah satunya adalah kemampuan koneksi matematis.

Kemampuan koneksi matematis dalam pembelajaran matematika juga merupakan salah satu tujuan pembelajaran matematika di sekolah yang tercantum dalam lampiran III Permendikbud nomor 58 tahun 2014 tentang kurikulum 2013 SMP/MTs. Siswa diharapkan mampu :

(1) Memahami konsep matematika, menjelaskan keterkaitan antarkonsep dan menggunakan konsep maupun algoritma secara luwes, akurat, efisien dan tepat, dalam pemecahan masalah.

(2) Menggunakan pola sebagai dugaan dalam penyelesaian masalah, dan mampu membuat generalisasi berdasarkan fenomena atau data yang ada.

(3) Menggunakan penalaran pada sifat, melakukan manipulasi matematika baik dalam penyederhanaan, maupun menganalisa komponen yang ada dalam pemecahan masalah dalam konteks matematika maupun di luar matematika.

(4) Mengkomunikasikan gagasan, penalaran serta mampu menyusun bukti matematika dengan menggunakan kalimat lengkap, simbol, table, diagram, atau media lain untuk memperjelas keadaan atau masalah.

(5) Memiliki sikap menghargai kegunaan matematika dalam kehidupan, yaitu memiliki rasa ingin tahu, perhatian, dan minat dalam mempelajari matematika, serta sikap ulet dan percaya diri dalam pemecahan masalah.

Berdasarkan tujuan pembelajaran matematika menurut Permendikbud dan standar proses dalam pembelajaran menurut NTCM, kemampuan koneksi matematis merupakan salah satu kemampuan yang harus dimiliki dan dikuasai oleh siswa. Kemampuan koneksi matematis diperlukan siswa karena matematika merupakan satu kesatuan, di mana konsep yang satu berhubungan dengan konsep yang lain. Selain itu matematika juga tidak bisa terpisah dari ilmu selain matematika dan masalah-masalah yang terjadi dalam kehidupan sehari-hari. Tanpa kemampuan koneksi matematis, siswa harus belajar dan mengingat terlalu banyak konsep dan prosedur matematika yang saling terpisah. Apabila siswa mampu mengaitkan ide-ide matematika maka pemahaman matematikanya akan semakin dalam dan bertahan lama karena mereka mampu melihat keterkaitan antar topik dalam matematika, dengan konteks selain matematika, dan dengan pengalaman hidup sehari-hari. 
SMPN 206 Jakarta yang merupakan salah satu sekolah menengah di daerah Jakarta Barat. Rendahnya kemampuan koneksi matematis siswa juga terlihat dari hasil rerata Ujian Nasional pada pelajaran matematika di SMP Negeri 206 Jakarta dalam dua tahun terakhir. Salah satu aspek yang diukur dalam soal ujian nasional adalah kemampuan koneksi matematis. Adapun indikator pemecahan masalah matematis mengacu pada indikator koneksi matematis menurut Suryabrata yaitu memahami hubungan antar konsep dalam matematika, memahami hubungan antar topik dalam matematika, memahami hubungan matematika dengan disiplin ilmu lain, menerapkan matematika dalam kehidupan sehari-hari (Suryabrata, 2015). Berikut hasil rerata ujian nasional di SMP Negeri 206 Jakarta tahun ajaran 2017/2018 dan 2018/2019 dalam mata pelajaran yang dipaparkan dalam Tabel 1

Tabel 1. Rata-rata Hasil UN Matematika di SMP 206 Jakarta

\begin{tabular}{|c|c|c|c|}
\hline No & Jumlah Peserta & Tahun Ajar & Rata-Rata \\
\hline 1 & 248 & $2017 / 2018$ & 66,46 \\
\hline 2 & 250 & $2018 / 2019$ & 69,03 \\
\hline
\end{tabular}

Dari hasil rata-rata ujian nasional di SMP Negeri 206 Jakarta tersebut membuktikan bahwa prestasi kemampuan koneksi siswa masih tergolong rendah. Selain itu, hasil observasi dan wawancara yang dilakukan dengan salah satu guru di SMP Negeri 206 Jakarta dipeeroleh informasi bahwa prestasi siswa kelas VIII dalam aspek kemampuan koneksi matematis siswa belum optimal. Rendahnya kemampuan koneksi matematis siswa kelas VIII SMP Negeri 206 Jakarta juga tercermin dari hasil penilaian akhir semester (PAS) semester ganjil tahun ajaran 2019/2020. Nilai rata-rata dari penilaian akhir semester (PAS) semester ganjil siswa kelas VIII SMP Negeri 206 bernilai 64,19.

Rendahnya kemampuan koneksi matematis siswa akan mempengaruhi kualitas belajar siswa dan berdampak pada rendahnya prestasi siswa di sekolah. Melatih siswa dalam menjelaskan keterkaitan antar konsep dan mengaplikasikan konsep, secara luwes, akurat, efisien, dan tepat dalam pemecahan masalah bukanlah hal yang mudah bagi seorang guru. Suatu upaya guru untuk meningkatkan kemampuan koneksi matematis siswa dapat digunakan berbagai macam strategi, metode, model ataupun teknik pembelajaran. Ruseffendi mengemukakan bahwa dengan menggunakan teknik atau metode mengajar, kemungkinan siswa akan lebih aktif belajar karena sesuai dengan gaya belajar siswa, dapat meningkatkan semangat dan lain-lain (Fitria, 2014).

Akan tetapi, model pembelajaran yang digunakan guru pada saat ini masih berpusat pada guru dengan alasan mudah diaplikasikan di kelas. Sehingga banyak siswa yang merasa bosan, kurang mengerti konsep matematika yang diajarkan di kelas, tidak senang dengan matematika serta tidak mengetahui kegunaan konsep matematika pada kehidupan sehari-hari. Oleh karena itu, pemilihan model pembelajaran yang akan dilaksanakan pada kegiatan pembelajaran harus tepat agar konsep matematika yang diajarkan dapat diterima dan dipahami dengan baik oleh siswa dan dapat mempengaruhi kemampuan koneksi matematisnya. Model pembelajaran yang berpusat pada siswa akan membuat siswa menjadi lebih terlibat aktif dalam pembelajaran di kelas dan merangsang proses berpikir kreatif siswa. 
Salah satu model pembelajaran yang berpusat pada siswa dan menekankan keaktifan pada diri siswa adalah model CORE (Connecting, Organizing, Reflecting, Extending). Model CORE mencakup empat proses, yaitu Connecting (menghubungkan), Organizing (mengorganisasikan), Reflecting (memikirkan kembali), dan Extending (memperluas pengetahuan). Dalam Connecting, siswa diajak untuk dapat menghubungkan pengetahuan baru dengan pengetahuannya terdahulu. Selanjutnya, tahap Organizing membantu siswa untuk dapat mengorganisasikan pengetahuannya. Pada tahap Reflecting, siswa dilatih untuk dapat menjelaskan kembali informasi yang telah mereka dapatkan. Terakhir yaitu tahap Extending atau proses memperluas pengetahuan bagi siswa, salah satunya dengan jalan diskusi. Tahapan pembelajaran dengan model CORE menawarkan sebuah proses pembelajaran yang berbeda dan memberi ruang bagi siswa untuk berpendapat, mencari solusi serta membangun pengetahuannya sendiri. Melalui model pembelajaran CORE ini, diharapkan mampu mempengaruhi kemampuan koneksi matematis siswa SMP agar siswa dapat merasakan manfaat belajar matematika, lebih dapat memahami konsep yang diajarkan, lebih senang dan nyaman dalam mempelajari matematika di kelas ataupun di rumah, karena matematika sangat erat kaitannya dengan permasalahan kehidupan seharihari dan banyak materi yang berkaitan satu sama lainnya.

Berdasarkan penjelasan latar belakang di atas, penulis terdorong untuk melakukan penelitian dengan judul "Pengaruh Model Pembelajaran CORE (Connecting, Organizing, Reflecting, Extending) terhadap Kemampuan Koneksi Matematis Siswa SMP Negeri 206 Jakarta”.

\section{METODE}

Penelitian ini menggunakan penelitian eksperimen semu atau quasi experimental design. Menurut Lestari dalam penelitian khususnya terkait pendidikan/pembelajaran, desain ini merupakan desain yang paling mungkin untuk dilakukan, mengingat terdapat berbagai macam kendala dalam menerapkan true experimental (Lestari, 2015). Desain true experimental terkadang sulit diterapkan dalam penelitian di bidang pendidikan, mengingat subjek/objek dalam penelitiannya adalah manusia, di mana sulit ditemukan manusia yang memiliki karakteristik yang sama, bahkan yang kembar sekalipun (Lestari, 2015).

Peneliti menggunakan subjek yang terdapat pada kelas tersebut dan tidak mengacak subjek yang ada serta tidak membentuk kelas baru. Penelitian quasi experimental design ini dilakukan dengan pemberian perlakuan (treatment) kepada suatu kelas yang selanjutnya disebut dengan kelas eksperimen dan akan diperbandingkan dengan kelas kontrol.

Desain penelitian yang digunakan adalah the nonequivalent posttest only control group design. Sampel pada jenis penelitian ini terdapat dua kelas yang digunakan yaitu kelas eksperimen dan kelas kontrol. Kedua kelas tersebut adalah kelas yang relatif homogen. Kelas eksperimen memperoleh perlakuan berupa model pembelajaran CORE, sedangkan kelas kontrol memperoleh model pembelajaran konvensional. 
Pengambilan sampel pada penelitian ini dilakukan dengan teknik probability sampling yaitu simple random sampling. Probabilty sampling adalah teknik pengambilan sampel yang memberikan peluang yang sama bagi setiap unsur/anggota populasi untuk dipilih menjadi anggota sampel (Lestari, 2015). Sedangkan simple random sampling adalah teknik pengambilan anggota sampel dari populasi yang dilakukan secara acak tanpa memperhatikan strata yang ada dalam populasi (Sugiyono 2011). Teknik pengambilan sampel dilakukan dengan memilih secara random dua dari enam kelas dalam populasi yang memiliki kesamaan rata-rata untuk dijadikan sebagai kelas eksperimen dan kelas kontrol. Sebelum menentukan dua kelas yang akan digunakan sebagai kelas eksperimen dan kelas kontrol, keempat kelas harus melewati uji Normalitas, Homogenitas dan kesamaan rata-rata untuk mengetahui kondisi awal. Data yang akan dijadikan sebagai data awal adalah nilai Penilaian Akhir Semester (PTS) semester ganjil tahun ajaran 2019/2020.

Setelah hasil dari uji tersebut menunjukan bahwa kondisi awal kelas relatif sama dan homogen, peneliti kemudian menggunakan teknik simple random sampling untuk menentukan dua kelas yang digunakan sebagai kelas sampel dalam penelitian ini. Kemudian, dilakukan pengundian terhadap dua kelas yang terpilih untuk menentukkan kelas mana yang menjadi kelas eksperimen dan kelas kontrol.

Tahap-tahap penentuan sampel dapat di lihat pada Gambar 1.

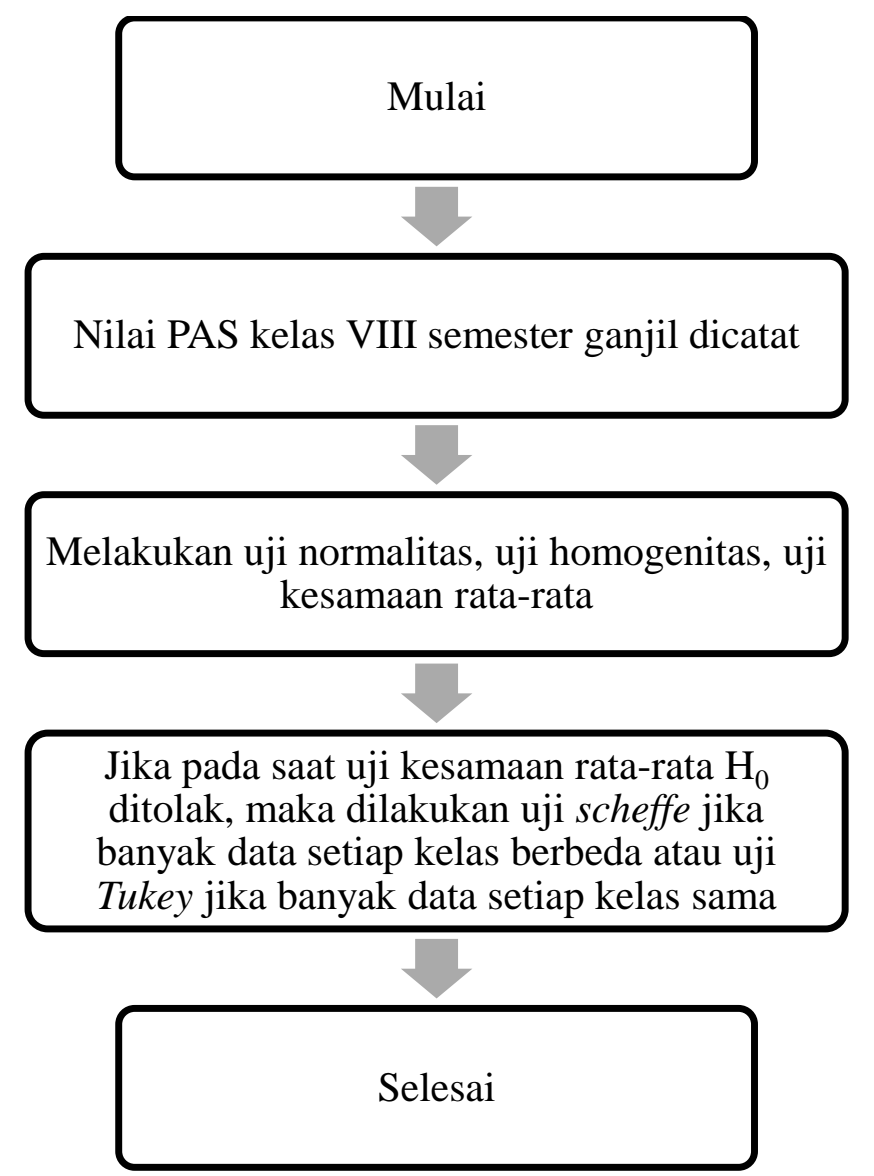

Gambar 1. Diagram Alur Pemilihan Subjek Penelitian 
Instrumen yang digunakan dalam penelitian ini adalah tes kemampuan koneksi matematis. Sebelum instrumen tes digunakan, tes tersebut diuji coba terlebih dahulu untuk mengetahui apakah soal tersebut memenuhi syarat soal yang baik, maka dilakukan pengujian validitas dan reliabilitas instrumen.

\section{HASIL DAN PEMBAHASAN}

\section{Hasil}

Uji Prasyarat Analisis Data Sebelum Perlakuan

Hasil uji normalitas sebelum perlakuan disajikan dalam Tabel 2.

Tabel 2. Hasil Uji Normalitas Sebelum Perlakuan

\begin{tabular}{|c|c|c|c|c|c|}
\hline Kelas & $\boldsymbol{L}_{\mathbf{0}}$ & $\boldsymbol{L}_{\text {tabel }}$ & Keterangan & Kesimpulan & Interpretasi \\
\hline VIII 1 & 0.071 & 0.148 & $L_{0}<L_{\text {tabel }}$ & Terima $H_{0}$ & Berdistribusi Normal \\
\hline VIII 2 & 0.095 & 0.148 & $L_{0}<L_{\text {tabel }}$ & Terima $H_{0}$ & Berdistribusi Normal \\
\hline VIII 3 & 0.078 & 0.148 & $L_{0}<L_{\text {tabel }}$ & Terima $H_{0}$ & Berdistribusi Normal \\
\hline VIII 4 & 0.123 & 0.148 & $L_{0}<L_{\text {tabel }}$ & Terima $H_{0}$ & Berdistribusi Normal \\
\hline VIII 5 & 0.099 & 0.148 & $L_{0}<L_{\text {tabel }}$ & Terima $H_{0}$ & Berdistribusi Normal \\
\hline
\end{tabular}

Berdasarkan Tabel 2, diketahui bahwa seluruh kelas yang diuji memiliki nila $\mathrm{L}_{0}<\mathrm{L}_{\text {tabel }}$, artinya keputusan terima $H_{0}$. Hal ini memberikan kesimpulan bahwa kelima kelas yaitu VIII 1, VIII 2, VIII 3 , VIII 4, dan VIII 5 berdistribusi normal. Hasil uji homogenitas sebelum perlakuan disajikan Tabel 3.

Tabel 3. Hasil Uji Homogenitas Sebelum Perlakuan

\begin{tabular}{|c|c|c|}
\hline$X^{2}$ hitung & $X^{2}{ }_{\text {hitung }}$ & Interpretasi \\
\hline 8,470 & 9,490 & Homogen \\
\hline
\end{tabular}

Berdasarkan Tabel 3, diketahui bahwa nilai $X^{2}{ }_{\text {hitung }}<X^{2}$ tabel, artinya keputusan terima $H_{0}$. Hal ini memberikan kesimpulan bahwa kelima kelas yaitu VIII 1, VIII 2, VIII 3, VIII 4, dan VIII 5 memiliki varians yang sama atau homogen.

Hasil uji kesamaan rata-rata disajikan dalam Tabel 4.

Tabel 4. Hasil Uji Kesamaan Rata-rata

\begin{tabular}{|c|c|c|c|c|}
\hline Kelas & $\boldsymbol{F}_{\boldsymbol{s}}$ & $\boldsymbol{F}_{\text {tabel }}$ & Keterangan & Kesimpulan \\
\hline VIII 1 dan VIII 2 & 0.1437 & 2.42 & $F_{s}<F_{\text {tabel }}$ & Terima $H_{0}$ \\
\hline VIII 1 dan VIII 3 & 0.3947 & 2.42 & $F_{S}<F_{\text {tabel }}$ & Terima $H_{0}$ \\
\hline VIII 1 dan VIII 4 & 2.366 & 2.42 & $F_{S}<F_{\text {tabel }}$ & Terima $H_{0}$ \\
\hline VIII 1 dan VIII 5 & 2.7081 & 2.42 & $F_{S}>F_{\text {tabel }}$ & Terima $H_{0}$ \\
\hline VIII 2 dan VIII 3 & 1.0149 & 2.42 & $F_{S}<F_{\text {tabel }}$ & Terima $H_{0}$ \\
\hline VIII 2 dan VIII 4 & 1.3434 & 2.42 & $F_{S}<F_{\text {tabel }}$ & Terima $H_{0}$ \\
\hline VIII 2 dan VIII 5 & 1.6338 & 2.42 & $F_{S}<F_{\text {tabel }}$ & Terima $H_{0}$ \\
\hline VIII 3 dan VIII 4 & 4.6936 & 2.42 & $F_{S}>F_{\text {tabel }}$ & Terima $H_{0}$ \\
\hline VIII 3 dan VIII 5 & 5.224 & 2.42 & $F_{S}>F_{\text {tabel }}$ & Terima $H_{0}$ \\
\hline VIII 4 dan VIII 5 & 0.0142 & 2.42 & $F_{S}<F_{\text {tabel }}$ & Terima $H_{0}$ \\
\hline
\end{tabular}

Pasangan kelas yang memiliki kesamaan rata-rata ialah kelas yang memiliki $F_{S}<F_{\text {tabel }}$, artinya keputusan terima $H_{0}$. Pasangan kelas yang menunjukkan terima $H_{0}$ yaitu kelas VIII 
1 dan VIII 2, VIII 1 dan VIII 3, VIII1 dan VIII 4, VIII 2 dan VIII 3, VIII 2 dan VIII 4, VIII 2 dan VIII 4, VIII 2 dan VIII 5, VIII 4 dan VIII 5. Hal ini menunjukkan bahwa kelas VIII 3 yang menyebabkan perbedaan rata-rata, sedangkan keempat kelas lainnya (kelas VIII 1, VIII 2, VIII 4, VIII 5) memiliki rata-rata yang sama. Oleh karena itu, dari empat kelas tersebut dapat dipilih dua kelas menggunakan teknik cluster random sampling dimana satu kelas sebagai kelas kontrol (VIII 4) dan satu kelas sebagai kelas eksperimen (VIII 5).

Uji Prasyarat Analisis Data Setelah Perlakuan

Hasil uji normalitas setelah perlakuan disajikan dalam Tabel 5.

Tabel 5. Hasil Uji Normalitas Setelah Perlakuan

\begin{tabular}{|c|c|c|c|c|c|c|}
\hline Kelas & $\boldsymbol{n}$ & $\boldsymbol{L}_{\mathbf{0}}$ & $\boldsymbol{L}_{\text {tabel }}$ & Keterangan & Kesimpulan & Interpretasi \\
\hline VIII 5 & 36 & 0,097 & 0,148 & $L_{0}<L_{\text {tabel }}$ & Terima $H_{0}$ & Normal \\
\hline VIII 4 & 36 & 0,106 & 0,148 & $L_{0}<L_{\text {tabel }}$ & Terima $H_{0}$ & Normal \\
\hline
\end{tabular}

Berdasarkan Tabel 5, diketahui bahwa kedua kelas yang diuji memiliki nilai $L_{0}<L_{\text {tabel }}$, artinya keputusan terima $H_{0}$. Hal ini memberikan kesimpulan bahwa kedua kelas yaitu VIII 4 dan VIII 5 berdistribusi normal. Hasil uji homogenitas setelah perlakuan disajikan dalam Tabel 6.

Tabel 6. Hasil Uji Homogenitas Setelah Perlakuan

\begin{tabular}{|c|c|c|c|}
\hline$F_{\text {hitung }}$ & $F_{(0.975,35,35)}$ & $F_{(0.025,35,35)}$ & Interpretasi \\
\hline 1,725 & 0,509 & 1,961 & Homogen \\
\hline
\end{tabular}

Berdasarkan Tabel 6, diketahui bahwa nilai $F_{(0.975,35,35)}<F_{\text {hitung }}<F_{(0.025,35,35)}$, artinya keputusan terima $H_{0}$. Hal ini memberikan kesimpulan bahwa kedua kelas yaitu VIII 4 dan VIII 5 memiliki varians yang sama atau homogen.

\section{Uji Analisis Data}

Hasil uji kesamaan rata-rata disajikan dalam Tabel 7.

Tabel 7. Hasil Uji-t Dua Sampel Independen

\begin{tabular}{|c|c|c|}
\hline$t_{\text {hitung }}$ & $t_{\text {tabel }}$ & Kesimpulan \\
\hline 1,745 & 1,667 & Tolak $H_{0}$ \\
\hline
\end{tabular}

Berdasarkan Tabel 7, diketahui bahwa nilai $t_{\text {hitung }}>t_{\text {tabel }}$, artinya keputusan tolak $H_{0}$. Oleh karena tolak $H_{0}$, maka dapat disimpulkan bahwa setelah perlakuan, rata-rata kemampuan koneksi matematis siswa kelas eksperimen lebih tinggi dari kelas kontrol dengan taraf signifikansi $\alpha=0.05$. Hal ini menunjukkan bahwa terdapat pengaruh signifikan penerapan pembelajaran CORE terhadap 
kemampuan koneksi matematis siswa SMP Negeri 206 Jakarta pada pokok bahasan Teorema Pythagoras dengan taraf signifikansi $\alpha=0.05$.

\section{Pembahasan}

Berdasarkan hasil pengujian hipotesis statistik, diperoleh informasi bahwa bahwa terdapat pengaruh signifikan model pembelajaran CORE (Connecting, Organizing, Reflecting, Extending) terhadap kemampuan koneksi matematis siswa SMP Negeri 206 Jakarta pada materi Teorema Pythagoras dengan taraf signifikansi $\quad \alpha=0,05$. Dari rata-rata hasil tes kemampuan koneksi matematis yang diujikan, terlihat bahwa kelas dengan model pembelajaran CORE memperoleh rata-rata 81.076, sedangkan kelas dengan model pembelajaran konvensional memperoleh rata-rata 74.843. Perbedaan rata-rata antar kedua kelas dipengaruhi oleh adanya perbedaan kegiatan pembelajaran.

Pada model pembelajaran CORE siswa melaksanakan pembelajaran dengan melewati empat langkah inti model pembelajaran tersebut. Langkah pertama ialah connecting. Pada tahap connecting guru membimbing siswa untuk menghubungkan konsep baru yang akan dipelajari dengan konsep lama yang telah dimilikinya dengan cara memberikan siswa pertanyaan-pertanyaan, kemudian siswa diminta untuk menulis hal-hal yang berhubungan dari pertanyaan tersebut. Hal ini dilakukan agar siswa dapat menemukan hubungan satu konsep dengan konsep lain dalam sebuah diskusi kelas, dimana konsep yang akan diajarkan dihubungkan dengan apa yang telah diketahui siswa.

Pada langkah kedua, yaitu organizing, siswa membentuk kelompok yang terdiri dari 4 sampai 5 orang untuk membuat peta konsep dan berdiskusi. Pada pertemuan pertama, proses transisi berlangsung cukup lama dan kurang tertib, namun pada pertemuan berikutnya proses transisi berlangsung cepat dan tertib. Hal ini disebabkan, siswa tidak terbiasa belajar secara berkelompok sehinggga proses transisi dalam pembentukkan kelompok pada awal pertemuan berlangsung cukup lama dan kurang tertib. Pada tahap ini siswa mengorganisasikan informasi-informasi yang diperolehnya secara berkelompok mengenai hubungan antara materi yang sudah dipelajari dengan materi yang akan dipelajari.

Langkah ketiga, yaitu reflecting. Pada tahap ini siswa memikirkan kembali informasi yang sudah didapat dan dipahaminya pada tahap Organizing. Dalam kegiatan diskusi, siswa diberi kesempatan untuk memikirkan kembali apakah hasil diskusi/hasil kerja kelompoknya pada tahap organizing sudah benar atau masih terdapat kesalahan yang perlu diperbaiki. Siswa bekerja sama untuk bersama-sama mendalami dan menggali hal-hal yang baru yang terkait dengan materi saat itu. Setelah itu siswa menyimpulkan dengan bahasa sendiri tentang materi yang baru dipelajari.

Tahap terakhir yaitu tahap extending. Guru mengarahkan siswa baik perorangan maupun kelompok melakukan pengembangan atau memperluas ide tersebut dan menggunakannya atau mengaplikasikannya dalam kehidupan sehari-hari, serta guru mengarahkan siswa untuk menemukan hal-hal baru yang terkait dengan materi yang dibahas. Pada fase ini diberikan kesempatan bagi siswa untuk mensintesis pengetahuan mereka, mengorganisasikannya dengan cara yang baru, dan 
mengubahnya menjadi aplikasi yang baru. Penerapannnya berupa kegiatan latihan mandiri untuk mengukur kemampuan individu.

Hal berbeda diterapkan pada kelas kontrol yang belajar dengan model pembelajaran konvensional. Pembelajaran dengan model konvensional tidak menerapkan diskusi antar siswa. Setiap pertemuan siswa diminta untuk membaca buku paket, mendengarkan penjelasan guru, serta mencatat materi yang diberikan guru. Siswa juga terlihat pasif saat guru memberi kesempatan siswa untuk bertanya mengenai materi yang dijelaskan, bahkan terkadang ada siswa yang tertidur saat proses pembelajaran berlangsung. Selanjutnya guru memberikan contoh soal latihan dari buku untuk dikerjakan. Terkadang hanya guru yang menyelesaikan soal tersebut di papan tulis dan siswa hanya menyalin di buku catatan. Hal ini menunjukkan bahwa peran guru masih dominan sehingga siswa pasif dalam pembelajaran.

Berdasarkan rangkaian kegiatan pembelajaran yang terjadi di kelas eksperimen dan kelas kontrol serta perannya terhadap kemampuan koneksi matematis, maka wajar jika rata-rata kemampuan koneksi matematis siswa kelas eksperimen lebih tinggi dari kelas kontrol. Dengan demikian, terdapat pengaruh signifikan model pembelajaran CORE (Connecting, Organizing, Reflecting, Extending) terhadap kemampuan koneksi matematis siswa SMP Negeri 206 Jakarta pada materi Teorema Pythagoras dengan taraf signifikansi $\alpha=0,05$.

\section{CONCLUSION}

Berdasarkan hasil pengujian hipotesis statistik diperoleh t_hitung=1.745>t_tabel=1,668 yang artinya tolak H_0 pada taraf signifikansi $\alpha=0.05$. Dengan demikian dapat disimpulkan bahwa terdapat pengaruh signifikan model pembelajaran CORE (Connecting, Organizing, Reflecting, Extending) terhadap kemampuan koneksi matematis siswa SMP Negeri 206 Jakarta pada materi Pythagoras dengan taraf signifikansi $\alpha=0,05$.

\section{REFFERENCES}

Fitria, N.N Skripsi: "Penerapan Teknik Probing-Prompting dalam Pembelajaran Matematika untuk Meningkatkan Kemampuan Koneksi Matematis Siswa SMP” Bandung: UPI, 2014

Lestari, Karunia Eka, M. Ridwan Yudhanegara, "Penelitian Pendidikan Matematika”, Bandung: PT Refika Aditama, 2015

Sugiyono, "Metode Penelitian Pendidikan". Bandung: Alfabeta, 2011

Suryabrata, "Metodologi Penelitian", Jakarta: Rajawali Press, 2015

The National Council of Teachers of Mathematics (NCTM). Principles and Standards for School Mathematics. Reston, VA: NCTM, 2000 
How to cite : Sigit, G. N., Fariani, H. I., \& Aris, H. W., 2020. Pengaruh Model Pembelajaran CORE (Connecting, Organizing, Reflecting, Extending) terhadap Kemampuan Koneksi Matematis Siswa di SMP Negeri 206 Jakarta. Jurnal Riset Pendidikan Matematika Jakarta. 2(1). 84-93. https://doi.org/10.21009/jrpmj.v2i1.12128

To link to this article: https://doi.org/10.21009/jrpmj.v2i1.12128 